\title{
Qualidade de alface crespa cultivada em sistema orgânico, convencional e hidropônico
}

\author{
Eliana Mara NCP da Silva; Regina Lúcia F Ferreira; Sebastião Elviro de Araújo Neto; Leonardo B \\ Tavella; Antônio JS Solino \\ UFAC, BR 364 km 04, 69915-900 Rio Branco-AC; eliananapoli@hotmail.com; reginalff@yahoo.com.br; selviro2000@yahoo.com.br; \\ leo_tavella@hotmail.com; jussiesolino@hotmail.com
}

\section{RESUMO}

O objetivo deste trabalho foi avaliar a qualidade da alface do grupo crespa, cv. Vera, em sistemas de cultivo orgânico, convencional e hidropônico em Rio Branco-AC. O experimento foi conduzido em julho de 2009. As amostras dos sistemas, convencional e hidropônico (3 marcas comerciais), foram escolhidas aleatoriamente nos supermercados do município de Rio Branco, no mesmo dia de coleta da alface produzida em sistema orgânico. A alface orgânica, produzida na área experimental do Setor de Agricultura Ecológica da Universidade Federal do Acre (UFAC), em Rio Branco, foi cultivada em estufa, sob plantio direto utilizando folhas de bambu como cobertura do solo, e adubada com composto orgânico ( $17 \mathrm{t} \mathrm{ha}^{-1} \mathrm{em}$ base seca). $\mathrm{O}$ delineamento utilizado foi o inteiramente casualizado, com cinco tratamentos e quatro repetições compostas por três plantas. As amostras foram lavadas, cortadas e processadas com folha e caule, para obter o suco. Logo após foram determinados os teores de sólidos solúveis e a concentração de nitrato e ácido ascórbico. As três marcas de alface hidropônica apresentaram maior teor de nitrato e menor concentração de sólidos solúveis e ácidos ascórbico, enquanto a alface orgânica apresentou qualidade superior, com baixa concentração de nitrato e maior teor de ácido ascórbico.

Palavras-chave: Lactuca sativa L., nitrato, alimento orgânico.

\begin{abstract}
Quality of looseleaf lettuce in organic, conventional and hydroponic crop in Rio Branco State, Brazil

The aim of this work was to evaluate the quality of the looseleaf lettuce group, cv. Vera, in organic, conventional and hydroponic crop in Rio Branco, Acre State, North Brazil. The experiment was carried out in July 2009, at the Universidade Federal do Acre. The samples of the conventional and hydroponic (three trademarks) systems were obtained randomly in supermarkets in Rio Branco, in the same day of harvest of the lettuce produced in the organic system. The organic lettuce grown in the experimental area was cultivated in a greenhouse, under no-tillage and mulching of bamboo leaves, and fertilized with organic compost (17 t/ha on a dry base). The experimental design was completely randomized with five treatments and four replications composed of three plants each. The samples were washed, cut and processed, including leaves and stems to obtain the juice and soon after the soluble solids contents and the concentration of nitrate and ascorbic acid were determined. The three trademarks of hydroponic lettuce had higher nitrate content and lower concentration of soluble solids and ascorbic acid, while the organic lettuce had higher quality, with low concentration of nitrate and higher ascorbic acid content.
\end{abstract}

Keywords: Lactuca sativa L., nitrate, organic food.

\section{(Recebido para publicação em 30 de setembro de 2010; aceito em 9 de maio de 2011)}

(Received on September 30, 2010; accepted on May 9, 2011)

$\mathrm{N}$ o final da última década, a qualidade do alimento passou a ser considerada fator de segurança alimentar e nutricional, sendo relacionada não só à produção do alimento em quantidade suficiente e acesso garantido, mas também à promoção do estado de saúde daqueles que o consomem. Surge, portanto, a compreensão de que não há segurança alimentar se o consumidor não dispuser de produtos sem agentes que possam oferecer risco à sua saúde, sob a forma de contaminação química ou biológica (Nardin et al., 1997).

Na produção orgânica de hortaliças, o agricultor é obrigado a não utilizar agrotóxico e fertilizante químico de alta concentração e solubilidade, e utilizar tecnologias (princípios e processos) conservacionistas (Brasil, 2010). Esse sistema de produção, além de não prejudicar o meio ambiente, gera produtos mais valorizados no mercado por serem alimentos de qualidade superior (Souza \& Resende, 2006), utilizando como práticas agrícolas biofertilizantes, composto e outros adubos orgânicos, defensivos alternativos (caldas, óleos e extratos naturais), cultivos consorciados, adubação verde, rotação de culturas, plantio direto, e variedades tolerantes e adaptadas.

Um produto orgânico é muito mais que um alimento sem agrotóxicos e sem aditivos químicos, visto que é o resultado de um sistema de produção agrícola que busca manejar, de forma equilibrada, o solo e os demais recursos naturais (água, plantas, animais, inse- tos), conservando-os a longo prazo e mantendo a harmonia desses elementos entre si e os seres humanos (Kathounian, 2001). Por isso, um produto orgânico não deveria ser visto apenas como uma oportunidade de mercado (Primavesi, 2001).

Por não usar adubos químicos de alta solubilidade e alta concentração, como os adubos nitrogenados (uréia, nitratos de cálcio, sulfato de amônio), potássicos (cloreto de potássio) e fosfatados (superfosfato simples ou triplo), os alimentos orgânicos são mais fibrosos e possuem maior concentração de matéria seca. Por isso, além da qualidade superior, ao comprar alimento orgânico, o consumidor estará levando uma quantidade maior de nutrientes 
(Souza \& Resende, 2006).

Atualmente, o consumidor está mais consciente em consumir alimentos com propriedades funcionais, como as frutas e hortaliças (Mattos et al., 2009). Porém, $78 \%$ de alguns tipos de frutas e hortaliças podem conter alto índice de contaminação por agrotóxicos (Gorenstein, 2004), sendo a alface, vagem, repolho, pêssego e melão alguns dos principais alimentos afetados por princípios ativos tóxicos não registrados. Além da contaminação por agrotóxicos, as plantas podem ter sua composição química alterada, como, por exemplo, a concentração de nitratos (carcinogênico). Cometti et al. (2004) revelam que a concentração de nitrato em plantas de alface produzidas em hidroponia é até 7,2 vezes maior que no sistema orgânico. Existe registro de teores de nitrato em alface hidropônica de até $11.600 \mathrm{mg} \mathrm{kg}^{-1}$ de massa fresca (Darolt, 2003).

$\mathrm{O}$ nitrato pode tornar-se tóxico ao seres vivos quando reduzido a nitrito que, por sua vez, no ambiente ácido do estômago reage com certas aminas, provenientes de várias fontes, incluindo o próprio alimento, dando origem a nitrosaminas, os quais são compostos cancerígenos, teratogênicos e mutagênicos (Maynard et al., 1976).

A alface tem grande importância na alimentação e na saúde humana destacando-se, principalmente, como fonte de vitaminas e sais minerais, e por constituir-se na mais popular hortaliça folhosa. Esse valor se deve não só ao sabor e qualidade nutritiva, como também pela facilidade de aquisição, produção durante o ano todo e baixo custo (Oliveira et al., 2004). Além disso, as alfaces são ricas em folato e contêm uma quantidade útil de betacaroteno, além de vitamina $\mathrm{C}$, potássio e certos fitoquímicos, como os flavonóides e lactucina (Collins, 2004). Porém, a segurança alimentar é tão importante quanto a composição de nutrientes encontrados nos alimentos, os quais devem ser livres de toda e qualquer substância química, natural ou contaminante causador de danos à saúde do consumidor (Chitarra \& Chitarra, 2005).

O objetivo deste trabalho foi avaliar a qualidade da alface do grupo crespa, cv. Vera, em sistemas de cultivo orgâni- co, convencional e hidropônico em Rio Branco, Acre.

\section{MATERIAL E MÉTODOS}

O experimento foi conduzido em julho de 2009, na Unidade de Tecnologia de Alimentos da Universidade Federal do Acre. Foram avaliadas alfaces do grupo crespa, cv. Vera de três sistemas de cultivo: orgânico, hidropônico e convencional.

Do sistema hidropônico foram testadas três marcas do mercado, codificadas como A, B e C. As alfaces cultivadas em sistemas convencional e hidropônico foram obtidas aleatoriamente nos supermercados no município de Rio Branco-AC, em 06 de julho de 2009, logo após a entrega pelos fornecedores das lojas, encaminhadas imediatamente para a Unidade de Tecnologia de Alimentos da Universidade Federal do Acre, e condicionadas em refrigerador a $8^{\circ} \mathrm{C}$.

A alface do sistema orgânico foi cultivada em estufa sobre plantio direto utilizando folhas de bambu como cobertura morta (mulching), com adubação de 17 t ha $^{-1}$ de composto orgânico, e irrigação por aspersão com lâmina de $6 \mathrm{~mm} \mathrm{dia}^{-1}$. Foram colhidas no mesmo dia da coleta da alface hidropônica e convencional e acondicionadas em refrigeração a $8^{\circ} \mathrm{C}$.

No dia seguinte, as amostras (folhas e caule) foram lavadas, cortadas em pedaços (picadas) e processadas em uma centrífuga com potência de $650 \mathrm{w}$, através de microtrituradores que facilitam o processo, mantendo separados os resíduos do suco do vegetal.

O suco foi analisado através dos teores de sólidos solúveis ( $\left.{ }^{0} \mathrm{Brix}\right)$, ácido ascórbico e teor de nitrato. O teor de sólidos solúveis foi determinado através da leitura direta em refratômetro digital, com compensação automática de temperatura. $\mathrm{O}$ teor de ácido ascórbico foi determinado de acordo com as normas analíticas do Instituto Adolfo Lutz (IAL, 1985).

A concentração de nitrato foi determinada através de $1 \mathrm{~g}$ de amostra do suco vegetal, misturada a $25 \mathrm{ml}$ de etanol a $80 \%$, e filtrada em papel de filtragem rápida. $\mathrm{O}$ filtrado foi transferido para o funil de separação, onde foi adicionado igual volume de clorofórmio, agitado suavemente, e deixado em repouso por 40 minutos para a completa separação. A fração apolar foi descartada e a polar foi recolhida, completada a $25 \mathrm{ml}$ com etanol a $80 \%$, e recolhida para as determinações (Fernandes, 1974).

$\mathrm{O}$ nitrato foi determinado a partir do kit de teste "Vacu-vials" para nitrato (K-6903 N-NO ${ }^{3}$ ), em que ocorre a redução do nitrato em nitrito através do uso de cádmio. Em solução acidificada, o nitrito diazotiza com uma amina aromática primária e se liga a outra molécula orgânica para produzir um "azo dye” de coloração intensa. A coloração resultante tem intensidade de cor em proporção direta com a concentração de nitrato na amostra. A leitura foi feita em espectrofotômetro (modelo V-2000) a $470 \mathrm{~nm}$.

O modelo estatístico utilizado foi em delineamento inteiramente casualizado, com cinco tratamentos e quatro repetições. Os dados foram submetidos à análise de variância e, ao se observar a significância do teste $\mathrm{F}$, a $5 \%$ de probabilidade do erro, utilizou-se o teste de Tukey, ao nível de 5\% de probabilidade, para a comparação das médias.

\section{RESULTADOS E DISCUSSÃO}

Houve efeito dos sistemas de cultivo nos teores de sólidos solúveis, ácido ascórbico e nitrato nas folhas de alface, encontrando-se o maior teor de ácido ascórbico e o menor teor de nitrato na alface orgânica (Tabela 1).

O teor de sólidos solúveis foi semelhante na alface produzida em sistema orgânico e convencional, e ambos apresentaram teores superiores que as alfaces das três marcas de hidropônicos.

A concentração de nitrato encontrada nas plantas de alface produzidas no sistema orgânico foi $41,3 \%$ menor que no sistema convencional, e 3,7 a 4,8 vezes menor que no sistema hidropônico. $\mathrm{Na}$ literatura, encontram-se relatos de teores de nitrato em alface maiores que os encontrados neste trabalho. Cometti et al. (2004) revelam que a concentração de nitrato em plantas de alface produzidas em hidroponia é até 7,2 vezes maior que no sistema orgânico. Miyazawa et al. (2001), comparando o sistema orgânico, o convencional e o 
Tabela 1. Teor de sólidos solúveis, ácido ascórbico e nitrato em alface produzida em cultivo orgânico, convencional e hidropônico (content of soluble solids, ascorbic acid and nitrate in lettuce produced in organic, conventional and hydroponic systems). Rio Branco, UFAC, 2009.

\begin{tabular}{lccc}
\hline Sistemas de cultivo & $\begin{array}{c}\text { Sólidos solúveis } \\
(\mathbf{\%})\end{array}$ & $\begin{array}{c}\text { Ácido ascórbico } \\
(\mathbf{m g} / \mathbf{1 0 0 g})\end{array}$ & $\begin{array}{c}\text { Nitrato (mg/ } \\
\mathbf{k g})\end{array}$ \\
\hline Orgânico & $3,5 \mathrm{ab}$ & $42,9 \mathrm{a}$ & $66,7 \mathrm{c}$ \\
Convencional & $4,0 \mathrm{a}$ & $29,7 \mathrm{bc}$ & $113,6 \mathrm{~b}$ \\
Hidropônico B & $2,9 \mathrm{~b}$ & $34,1 \mathrm{~b}$ & $331,8 \mathrm{a}$ \\
Hidropônico C & $3,0 \mathrm{~b}$ & $26,4 \mathrm{c}$ & $254,0 \mathrm{a}$ \\
Hidropônico A & $2,9 \mathrm{~b}$ & $28,6 \mathrm{bc}$ & $249,3 \mathrm{a}$ \\
\hline Média & 3,3 & 32,3 & 203,1 \\
\hline CV (\%) & 7,91 & 9,46 & 26,0 \\
\hline
\end{tabular}

Médias seguidas pela mesma letra, na mesma coluna, não diferem estatisticamente entre si ao nível de $5 \%$ de probabilidade pelo teste de Tukey (means followed by the same letter in the column did not differ from each other, Tukey test, $5 \%$ ).

hidropônico, mostraram que o teor de nitrato nas folhas de alface variou entre 250 e $11.600 \mathrm{mg} / \mathrm{kg}$, sendo que as folhas com menor concentração de nitrato foram aquelas cultivadas em sistema de produção orgânico.

Os principais fatores fisiológicos responsáveis pelo acúmulo de nitrato em hortaliças são a capacidade de redução do $\mathrm{NO}_{3}^{-}$e o consumo de luxo. Assim o estado de estresse causado pela temperatura, luminosidade e seca reduz a capacidade de redução do $\mathrm{NO}_{3}^{-}$. O aumento da disponibilidade de $\mathrm{NO}_{3}^{-}$ocorre do sistema orgânico para o hidropônico (Cometti et al., 2004; Cavarianni et al., 2008). No cultivo de alface em sistema hidropônico, o fertilizante nitrogenado é fornecido principalmente na forma de nitrato dissolvido na água, fato que facilita a absorção pela raiz, de quantidades muito acima da capacidade da planta de metabolizá-lo totalmente, acumulando, assim, o excedente no tecido vegetal (Fernandes et al., 2002).

De acordo com a FAO, o índice de máxima ingestão diária admissível (IDA) de nitrato é de $5 \mathrm{mg} / \mathrm{kg}$ de peso vivo, e $0,2 \mathrm{mg} / \mathrm{kg}$ de nitrito. Assim, a produção orgânica de alface atende a um dos princípios explícitos pela lei brasileira para produção dos alimentos orgânicos, a Lei $n^{\circ} 10.831$, de 23 de dezembro de 2003 que, em seu artigo primeiro, parágrafo primeiro, e inciso 1 , estabelece “.... a oferta de produtos saudáveis isentos de contaminantes intencionais" (Brasil, 2010).

Os teores de ácido ascórbico variaram de $26,4 \mathrm{mg} / 100 \mathrm{~g}$ em sistema hidropônico, a $42,9 \mathrm{mg} / 100 \mathrm{~g}$ em sistema orgânico (Tabela 1). Esta variação encontra-se dentro do padrão para alface, que varia sensivelmente em relação à prática de cultivo (Freire et al., 2009).

$\mathrm{O}$ menor teor de vitamina $\mathrm{C}$ encontrado na alface cultivada em sistema hidropônico se deve ao $\mathrm{N}$ prontamente disponível na solução aquosa, o que facilita a absorção deste pela planta. Segundo Lee \& Kader (2000), a crescente aplicação de fertilizantes nitrogenados tende a diminuir o teor de ácido ascórbico na maioria da hortaliças. A maior disponibilidade de nitrogênio implica em aumento da síntese de proteínas e carboidratos e, consequentemente, menor uso de fotoassimilados na produção de compostos do metabolismo secundário, como ácido ascórbico (Ramos, 2006). Além disso, deve-se considerar também o aumento da área foliar da planta proporcionado pela adubação nitrogenada, de forma a reduzir a intensidade luminosa no dossel e a produção de ácido ascórbico nas partes sombreadas, principalmente no sistema hidropônico onde esse nitrogênio é mais disponível (Ramos, 2006).

O teor de sólidos solúveis foi maior na alface do sistema convencional (4\%) que não diferiu estatisticamente do cultivo orgânico $(3,5 \%)$, e este não diferiu do hidropônico, visto que variaram entre 2,9 e $3 \%$ (Tabela 1 ).

Alguns autores consideram o teor de sólidos solúveis como um importante atributo para previsão do tempo de vida útil pós-colheita da alface (Varoquaux et al., 1996). Assim, quanto maior o teor de sólidos solúveis da alface recém-colhida, maior o período em que sua qualidade pode ser preservada, muito embora esta não seja uma característica de qualidade para alface, pois o consumidor não espera saborear uma alface adocicada, ao contrário da expectativa de saborear uma fruta típica de sobremesa, por exemplo.

De acordo com os resultados deste experimento conduzido no Acre, a alface cultivada em sistema orgânico apresentou qualidade superior, com menor concentração de nitrato e maior concentração de ácido ascórbico, em comparação ao sistema convencional e hidropônico.

\section{REFERÊNCIAS}

BRASIL. Ministério da Agricultura e Abastecimento. Lei no 10.831 , de 23 de dezembro de 2003. Dispõe sobre a agricultura orgânica. Disponível em: <www.agricultura. gov.br>. Acesso em: 28 fevereiro 2010.

CAVARIANNI RL; CECÍLIO FILHO AB; CAZETTA JO; MAY A. 2008. Concentrações de nitrogênio na solução nutritiva e horários de colheita no teor de nitrato em rúcula. Revista Caatinga 21:44-49.

CHITARRA MIF; CHITARRA AB. 2005. Póscolheita de frutos e hortaliças: fisiologia e manuseio. 2. ed. ver. ampl. Lavras: UFLA.

COLLINS A. 2004. Lettuce: $A C$ diet food and nutrition. Disponível em: <http://www. annecollins.com/dietnutrition/lettuce $>$. Acessado em: 29 outubro 2009.

COMETTI NN; MATIAS GCS; ZONTA E; MARY W; FERNANDES MS. 2004. Comportamento de nitrogenados e açúcares solúveis em tecidos de alface orgânica, hidropônica e convencional. Horticultura brasileira 22: 748-753.

DAROLT MR. 2003. A qualidade dos alimentos orgânicos. Disponível em: <http://www. planetaorganico.com.br $>$ Acesso em: 20 setembro 2005.

FERNANDES MS. 1974. Effects of light and temperature on the nitrogen metabolism of tropical rice. Michigan State University, Michigan. (Tese doutorado)

FERNANDES AA; MARTINEZ HEP; PEREIRA PRG; FONSECA MCM. 2002. Produtividade, acúmulo de nitrato e estado nutricional de cultivares de alface, em hidroponia, em função de fontes de nutrientes. Horticultura brasileira 20: 195-200.

FREIRE AG; OLIVEIRA FA; CARRILHO MJSO; OLIVEIRA MKT; FREITAS DC. 2009. Qualidade de cultivares de alface produzidas em condições salinas. Revista Caatinga 22: 81-88. 
GORENSTEIN O. 2004. Monitoramento de resíduos de agrotóxicos em frutas e hortaliças frescas comercializadas na CEAGESP: análise de resultados de 2003, SP, Brasil. Informações Econômicas 34.

INSTITUTO ADOLFO LUTZ. 1985. Normas analíticas do Instituto Adolfo Lutz. 3.ed. São Paulo.

LEE SK; KADER AA. 2000. Preharvest and postharvest factors influencing vitamin $\mathrm{C}$ content of horticultural crops. Postharvest Biology and Technology 20: 207-220.

KHATOUNIAN CA. 2001. A reconstrução ecológica da agricultura. Botucatu: Agroecologia, 348p.

MATTOS LM; MORETTI CL; MOURA MA; MALDONADE IR; SILVA EYY. 2009. Produção segura e rastreabilidade de hortaliças.
Horticultura brasileira, 27: 408-413.

MAYNARD DN; BARKER AV; MINOTTI PL; PECK NH. 1976. Nitrate accumulation in vegetables. Advances in Agronomy 28: 71-118.

MIYAZAWA M; KHATOUNIAN CA; ODENATH-PENHA LA. 2001. Teor de nitrato nas folhas de alface produzida em cultivo convencional, orgânico e hidropônico. Agroecologia Hoje 2: 23.

NARDIN MS; SILVA MV; OETTERER M. 1997. Segurança Alimentar: uma necessidade brasileira. Boletim da SBCTA 31: 68-76.

OLIVEIRAACB; SEDIYAMA MAN; PEDROSA MW; GARCIA NC; GARCIA SLR. 2004. Divergência genética e descarte de variáveis em alface cultivada sob sistema hidropônico. Acta Scientiarum Agronomy 26: 211-217.
PRIMAVESI A. 2001. A alimentação no século. XXI. In: ENCONTRO DE PROCESSOS DE PROTEÇÃO DE PLANTAS: CONTROLE ECOLÓGICO DE PRAGAS E DOENÇAS, 1. Anais... Botucatu: Agroecologia, p.7-12.

RAMOS MJM. 2006. Caracterização de sintomas de deficiência de macronutrientes e boro em abacaxizeiro cultivar Imperial. Rio de Janeiro: UENF. (Tese doutorado).

SOUZA JL; RESENDE PL. 2006. Manual de horticultura orgânica. 2 ed. Viçosa, MG: Aprenda Fácil. 843 p.

VAROQUAUX P; MAZOLLIER J; ALBAGNAC G. 1996. The influence of raw material characteristics on the storage life of freshcut butterhead lettuce. Postharvest Biology and Technology 9: 127-139. 